\title{
Resveratrol inhibits human nasopharyngeal carcinoma cell growth via blocking pAkt/p70S6K signaling pathways
}

\author{
MEIHONG ZHANG ${ }^{1,2}$, XIN ZHOU ${ }^{1}$ and KEYUAN ZHOU ${ }^{1,2}$ \\ ${ }^{1}$ Center for Gene Diagnosis, Zhongnan Hospital, Wuhan University, Wuhan, Hubei; \\ ${ }^{2}$ Key Laboratory for Medical Molecular Diagnostics of Guangdong Province, \\ Guangdong Medical College, Dongguan, Guangdong, P.R. China
}

Received September 29, 2012; Accepted November 15, 2012

DOI: $10.3892 /$ ijmm.2013.1237

\begin{abstract}
Resveratrol (trans-3,4',5-trihydroxystilbene) has been shown to exert potent anticancer effects on various types of cancer through its anti-proliferative, anti-angiogenic, antioxidant and pro-apoptotic functions. There is still a lack of experimental evidence regarding whether resveratrol has potential anticancer activity in human nasopharyngeal carcinoma (NPC) cells. The purpose of this study was to explore the anticancer activity of resveratrol in human NPC cells both in vitro and in vivo. Our results indicated that treatment with resveratrol led to a time- and dose-dependent decrease in cell proliferation in NPC cells. A dose-dependent increase in apoptosis in response to resveratrol treatment was also observed in NPC cells. Flow cytometric analysis showed that treatment of NPC cells with resveratrol led to cell cycle arrest at the $\mathrm{S}$ and $\mathrm{G} 2 / \mathrm{M}$ phases. Mechanistically, resveratrol treatment downregulated the expression of Bcl-2 and hypoxia-inducible factor- $1 \alpha(\mathrm{HIF}-1 \alpha)$ proteins and upregulated the expression of caspase-3 protein. In addition, resveratrol treatment also significantly decreased the phosphorylation levels of Akt1, p70S6K and p-4E-BP-1 and the protein expression of several cyclins involved in cell cycle regulation. In vivo studies further showed that resveratrol was able to significantly inhibit the growth of NPC tumor xenografts in nude mice. Collectively, our findings suggest that resveratrol exerts potent anti-proliferative and pro-apoptotic effects on human NPC cells possibly through interfering with the pAkt1/p70S6K signaling pathways, thus it may potentially be developed as an effective agent for chemoprevention and chemotherapy of human NPC.
\end{abstract}

\section{Introduction}

Nasopharyngeal carcinoma (NPC) is an epithelial malignancy characterized by the distinctive ethnic and geographic

Correspondence to: Professor Keyuan Zhou, Center for Gene Diagnosis, Zhongnan Hospital, Wuhan University, 169 Donghu Road, Wuhan, Hubei 430071, P.R. China

E-mail: mhzhang69@gmail.com

Key words: resveratrol, nasopharyngeal carcinoma, proliferation, apoptosis distribution. The annual incidence of this malignant disease of head and neck is approximately 20-50 cases/100,000 people, with most cases reported in Southeast Asia, Southern China, the Middle East and Northern Africa (1). Each year, approximately 80,000 new cases of NPC are diagnosed across the world, and 50,000 individuals succumb to this malignancy $(1,2)$. Accumulating evidence from epidemiology, clinical and pre-clinical studies suggests that multiple factors, including genetic and non-genetic factors such as genetic susceptibility, Epstein-Barr virus (EBV) infection, environmental and dietary factors, cooperatively contribute to the development of NPC (3). Due to the deep and silent anatomic location and atypical clinical symptoms and signs, NPC is often diagnosed at an advanced stage. Although the combination of radiotherapy and cisplatin-based chemotherapy has improved the 5-year survival rate of NPC patients, the overall prognosis, especially for advanced and metastatic NPC, remains poor due to the high recurrence and relapse rate $(2,4,5)$. Therefore, the molecular and signaling mechanisms underlying NPC pathogenesis urgently need to be elucidated and novel molecular targets for effective prevention and treatment of NPC remain to be identified.

Resveratrol, a natural polyphenolic phytoalexin derived from the skin of grapes and other fruits, is known to have potent anti-inflammatory and antioxidant effects (6). A growing body of evidence from numerous in vitro and in vivo studies has shown that resveratrol is able to modulate the activation/function of various molecular targets and signaling pathways involved in cell proliferation, apoptosis/survival, cell cycle, inflammation and angiogenesis, which may constitute the foundation for its potent inhibitory effects on tumor growth (7-9). Despite mounting evidence that resveratrol has antitumor effects on various types of cancer, the effect of resveratrol on NPC growth and the corresponding molecular mechanisms remain largely elusive. In the present study, we showed that resveratrol potently inhibited the proliferation and induced apoptosis in CNE-1 and CNE-2Z cells, two established human NPC cell lines. The therapeutic effects of resveratrol on NPC growth were further confirmed in a xenografted CNE-2Z tumor model in nude mice. Our findings suggest that resveratrol may have the potential to become a chemopreventive and/or treatment chemotherapeutic agent for human NPC. 


\section{Materials and methods}

Reagents and antibodies. Resveratrol and 3-(4,5-dimethylthiazol-2-yl)-2,5-diphenyltetrazolium (MTT) bromide were purchased from Sigma (St. Louis, MO, USA) and dissolved at a concentration of $100 \mathrm{mmol} / 1$ in $100 \%$ dimethyl sulfoxide (DMSO) as a stock solution, stored at $-20^{\circ} \mathrm{C}$. The final DMSO concentration did not exceed $0.1 \%$ throughout the study. Annexin V-FITC and primary antibody for human hypoxia-inducible factor- $1 \alpha$ (HIF-1 $\alpha$ ) was purchased from BD Transduction Laboratories (San Diego, CA, USA). Antibodies for p70S6K, p-4E-BP-1, caspase-3, Bcl-2, and $\beta$-actin were purchased from Santa Cruz Biotechnology, Inc., (Santa Cruz, CA, USA). Antibodies for cyclins A, B, D, E and cyclin-dependent kinases (CDK)/p34 were from New England Biolabs (Beverly, MA, USA). Horseradish peroxidase (HRP) conjugated secondary antibodies were obtained from Pierce (Rockford, IL, USA).

Cell culture. CNE-2Z, a poorly differentiated human NPC cell line, and CNE-1, a well differentiated human NPC cell line, were cultured in RPMI-1640 complete culture medium (Gibco, USA) supplemented with 15\% heat-inactivated fetal bovine serum (FBS; Gibco), penicillin $(100 \mathrm{U} / \mathrm{ml})$ and streptomycin $(100 \mu \mathrm{g} / \mathrm{ml})$ at $37^{\circ} \mathrm{C}$ in a humidified incubator with $5 \%$ $\mathrm{CO}_{2}(10)$.

Cell proliferation assay. The effect of resveratrol on the cell growth of CNE-1 and CNE-2Z cells was examined using the MTT assay. Cancer cells were plated in 96-well plates at $10^{4} \mathrm{cells} /$ well. Following pretreatment with different concentrations of resveratrol for 24 or $48 \mathrm{~h}$, viable cells were determined using the MTT Assay kit (Chemicon, Temecula, CA, USA) according to the manufacturer's protocol. At indicated timepoints, $20 \mu \mathrm{l}$ of MTT solution $(5 \mathrm{mg} / \mathrm{ml}$ in PBS) were added into each well and incubated for $4 \mathrm{~h}$. Then, $100 \mu \mathrm{l}$ of DMSO was added to dissolve the crystals. The plate was then left to stand for $10 \mathrm{~min}$ at room temperature and the corresponding absorbance was measured at $490 \mathrm{~nm}$. Each experiment was performed in triplicate.

Flow cytometric analysis. For the apoptosis analysis, NPC cells were plated into 6 -well plates $\left(2 \times 10^{5}\right.$ cells/well $)$ and cultured for $24 \mathrm{~h}$. Then cells were incubated with $50 \mu \mathrm{M}$ resveratrol for $48 \mathrm{~h}$. Subsequently, the trypsinized cells together with the medium were collected and centrifuged. The pelleted cells were washed and resuspended in PBS for flow cytometric analysis using the Annexin V-FITC/propidium iodide (PI) Apoptosis Detection kit according to the manufacturer's protocols (BD Biosciences).

For the cell cycle analysis, NPC cells were plated into 6 -well plates $\left(2 \times 10^{5}\right.$ cells/well) and cultured for $24 \mathrm{~h}$. Then cells were incubated with $50 \mu \mathrm{M}$ resveratrol for $48 \mathrm{~h}$. The cells were collected and washed with PBS 2 times, followed by resuspending in $1 \mathrm{ml}$ PBS. The cells were fixed with ethanol (70\%) for $2 \mathrm{~h}$, centrifuged, washed with PBS, and resuspended in $1 \mathrm{ml}$ of PI solution (0.1\% Triton X-100, $200 \mu \mathrm{g} / \mathrm{ml}$ RNase, $20 \mu \mathrm{g} / \mathrm{ml} \mathrm{PI}$ in $10 \mathrm{ml}$ of PBS) and incubated at room temperature for $30 \mathrm{~min}$. Cell cycle distribution was analyzed by flow cytometry.
Western blot analysis. Treated and untreated NPC cells were lysed with RIPA lysis buffer containing $20 \mathrm{mmol} / 1$ $\beta$-mercaptoethanol, $250 \mu \mathrm{mol} / \mathrm{l}$ sodium orthovanadate, $1 \mathrm{mmol} / \mathrm{l} \mathrm{PMSF}$ and complete protease inhibitor cocktail (Sigma), and incubated at $4^{\circ} \mathrm{C}$ for at least $1 \mathrm{~h}$. The lysates were ultra-sonicated and centrifuged at $14,000 \mathrm{x}$ g for $15 \mathrm{~min}$. The supernatants were collected and stored at $-70^{\circ} \mathrm{C}$. Protein concentrations were determined by BCA methods. Protein $(100 \mu \mathrm{g})$ was separated on $8-10 \%$ polyacrylamide-SDS gel and electroblotted onto nitrocellulose membranes (Bio-Rad). After blocking with TBS/5\% skim milk, the membrane was incubated overnight at $4{ }^{\circ} \mathrm{C}$ with specific primary antibodies (1:1,000-1:2,000) followed by incubation with HRP-conjugated secondary antibodies $(1: 5,000)$ for $1 \mathrm{~h}$ at room temperature, and signals were detected by ECL (10).

In vivo xenograft study. Six to eight-week-old female nude mice (BALB/c nu/nu) were purchased from the Animal Center of Southern Medical University (Guangzhou, China) and were housed in a sterile environment with a light/dark cycle of $12 / 12 \mathrm{~h}$ and were allowed free access to food and water for 1 week. All animal studies were performed following international guidelines on animal welfare and were approved by the Institutional Animal Care and Use Committee (IACUC) of Guangdong Medical College. CNE-2Z $\left(1 \times 10^{6}\right)$ cells in $0.1 \mathrm{ml}$ PBS were subcutaneously (s.c.) injected into the right hind flank of the mice. One week after inoculation of tumor cells $\left(\sim 100 \mathrm{~mm}^{3}\right)$, the tumor-bearing mice were randomly divided into the control and resveratrol $(20 \mathrm{mg} / \mathrm{kg}$ body weight) treatment groups $(\mathrm{n}=5 /$ group), whereby resveratrol dissolved in $200 \mu \mathrm{l}$ of $10 \%$ DMSO in PBS was intraperitoneally (i.p.) injected into mice once a day for 3 weeks. Control animals were injected with the vehicle (10\% DMSO in PBS). Tumor sizes were measured every other day with a caliper and were calculated as $1 / 2 \mathrm{x}$ length $\mathrm{x}$ width ${ }^{2}$ $\left(\mathrm{V}=\mathrm{LW}^{2} / 2 \mathrm{~mm}^{3}\right)$. At the end of the experiments, the mice were sacrificed and tumor tissues were excised for further analysis.

Statistical analysis. Data are expressed as the means \pm SD and were analyzed with the commercially available statistical software package, SPSS 13.0 (SPSS). One-way ANOVA or Student's t-test was performed. $\mathrm{P}<0.05$ was considered to indicate a statistically significant difference.

\section{Results}

Resveratrol inhibits proliferation of NPC cells. We first observed the effects of resveratrol on the proliferation of human NPC cells. CNE-1 and CNE-2Z cells were treated with increasing concentrations of resveratrol for 24 or $48 \mathrm{~h}$ followed by MTT assay. Our results indicated that resveratrol treatment led to a time- and dose-dependent reduction in the proliferation rate of both types of NPC cells, whereby at the concentrations of 50 and $100 \mu \mathrm{M}$, resveratrol exhibited more pronounced inhibitory effects on the proliferation of CNE-2Z cells than on that of CNE-1 cells (Fig. 1A and B). Additionally, we showed that resveratrol treatment inhibited colony formation of CNE-2Z cells in a dose-dependent manner (Fig. 1C). These results suggest that resveratrol has the potential to inhibit the proliferation of NPC cells with different differentiation grades. 

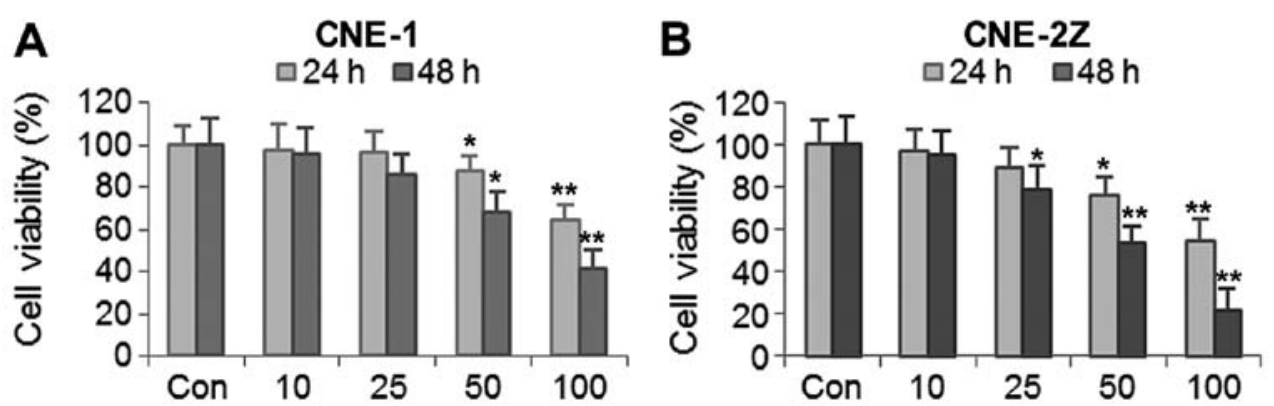

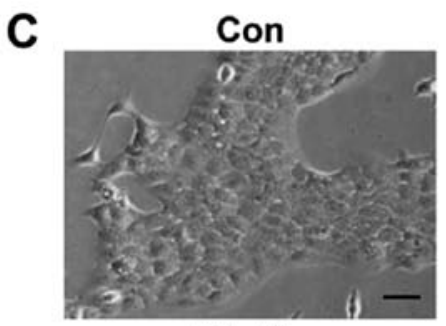

$50 \mu \mathrm{M}$

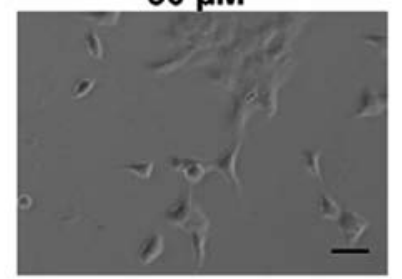

$10 \mu \mathrm{M}$

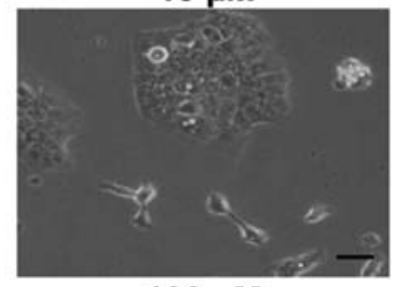

$100 \mu \mathrm{M}$

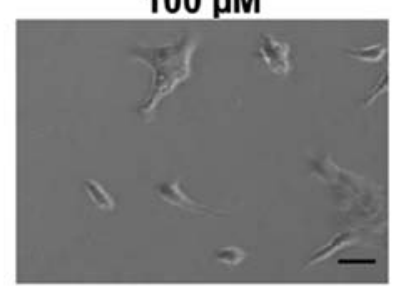

$25 \mu \mathrm{M}$

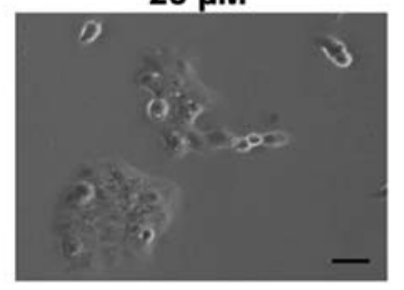

Figure 1. Resveratrol inhibits the proliferation of human NPC cells. (A and B) Human NPC cells, CNE-1 and CNE-2Z, were incubated with increasing concentrations of resveratrol $(0-100 \mu \mathrm{M})$ for 24 or $48 \mathrm{~h}$. Cell viability was determined by MTT assay. (C) CNE-2Z cells (1x10 $4 /$ well) were plated into 6 -well plates and cultured in the absence or presence of different concentrations of resveratrol for 7 days. Cell morphology was observed and documented under an inverted microscope with a digital imaging system. Bars, $200 \mu \mathrm{m}$. Data represent means $\pm \mathrm{SD}$ of 3 independent experiments. ${ }^{*} \mathrm{P}<0.05$; ${ }^{* * *} \mathrm{P}<0.01$.

Resveratrol induces apoptosis in NPC cells. Next, we investigated the effect of resveratrol on apoptosis in NPC cells. CNE-2Z cells were exposed to different concentrations of resveratrol for $48 \mathrm{~h}$, followed by determination of apoptosis using the Annexin V-FITC/PI staining kit and flow cytometric analysis. Compared with controls, resveratrol treatment resulted in a dose-dependent induction of apoptosis of CNE-2Z cells (Fig. 2), suggesting that resveratrol potently induces apoptosis of NPC cells.

Potential mechanisms underlying resveratrol-induced apoptosis and inhibition of proliferation in NPC cells. We then explored the potential mechanisms underlying resveratrolinduced apoptosis and inhibition of proliferation in NPC cells. To this end, CNE-2Z cells were treated with different concentrations of resveratrol for $16 \mathrm{~h}$ (overnight), and the expression of several important genes involved in the regulation of apoptosis was determined by western blot analysis. Resveratrol treatment significantly inhibited the protein expression of 2 anti-apoptotic genes, Bcl-2 and HIF-1 $\alpha(10,11)$, in CNE-2Z cells (Fig. 3A). On the other hand, resveratrol treatment led to a dose-dependent increase in the expression of caspase-3 which plays a critical role in apoptosis induction $(10,11)$. Since the pAkt1/p70S6K/p-4E-BP-1 signaling pathway plays an essential role in the maintenance of proliferation and survival of cancer cells (12), we then explored whether resveratrol can block the activation of this signaling pathway. Our results demonstrated that treatment of CNE-2Z cells with resveratrol led to dosedependent decrease in the phosphorylated levels of pAkt1, p70S6K as well as p-4E-BP-1 (Fig. 3B). These findings suggest that resveratrol inhibits proliferation and induces apoptosis of NPC cells possibly by blocking PI3K/Akt signaling pathways.

Effects of resveratrol on cell cycle distribution in NPC cells. We then explored whether resveratrol had any effect on the cell cycle distribution of NPC cells. CNE-1 and CNE-2Z cells were exposed to 10 and $50 \mu \mathrm{M}$ of resveratrol for $24 \mathrm{~h}$ and cell cycle distribution was analyzed with flow cytometry. Compared with controls, treatment of CNE-1 cells with resveratrol at $10 \mu \mathrm{M}$ showed no obvious effects on the cell cycle distribution (P>0.05), while at $50 \mu \mathrm{M}$, resveratrol treatment significantly reduced the percentage of G1-phase cells (from 72.5 \pm 9.4 to $42.1 \pm 8.6 \% ; \mathrm{P}<0.01)$ and increased the percentage of $\mathrm{S}$-phase cells (from $13.1 \pm 6.1$ to $45.8 \pm 7.2 \%$; $\mathrm{P}<0.05$ ) (Fig. 4A, upper panel). Additionally, we showed that resveratrol exhibited stronger regulatory effects on cell cycle distribution in CNE-2Z cells. Compared with controls, treatment of CNE-2Z cells with resveratrol even at $10 \mu \mathrm{M}$ led to a significant reduction in the percentage of G1-phase cells (from $70.3 \pm 8.3$ to $52.6 \pm 6.5 \%$; $\mathrm{P}<0.05)$ and a marked increase in the percentage of S-phase cells (from $12.8 \pm 4.1$ to $32.3 \pm 7.8 \%$; $\mathrm{P}<0.05$ ), but had no obvious effects on the percentage of $\mathrm{G} 2 / \mathrm{M}$-phase cells $(\mathrm{P}>0.05)$ 


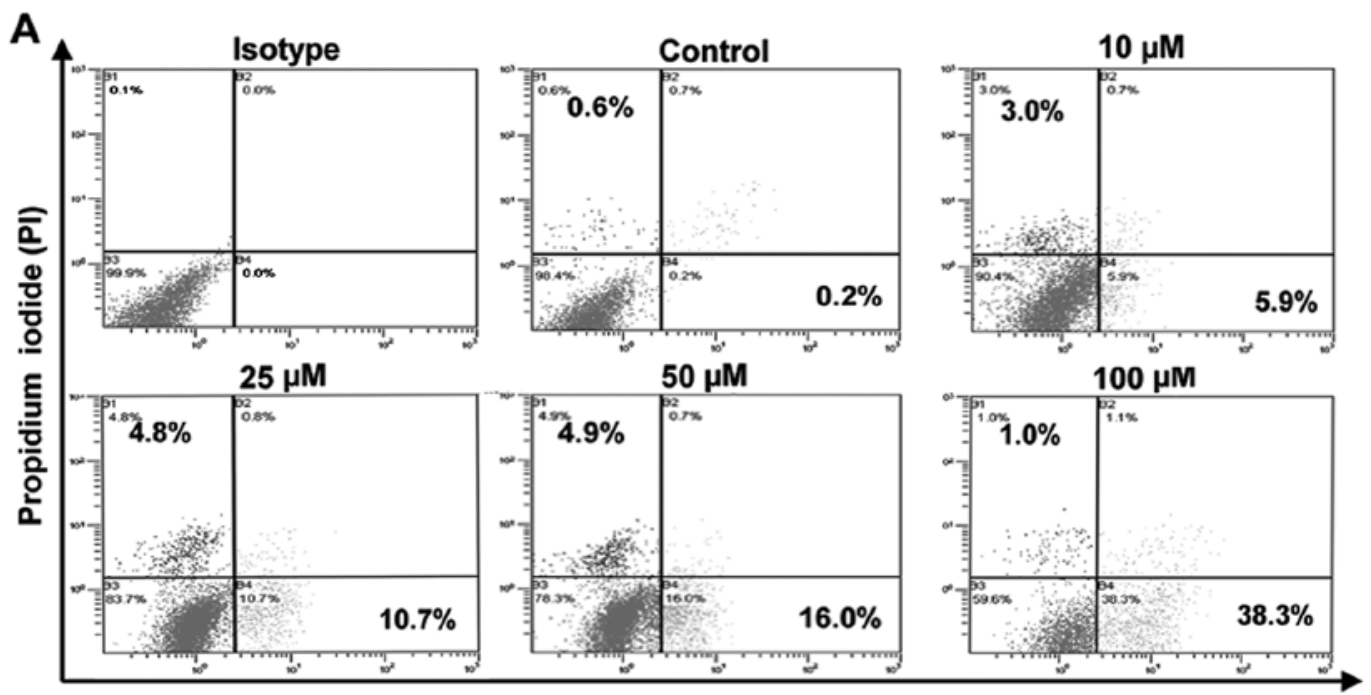

Annexin V-FITC

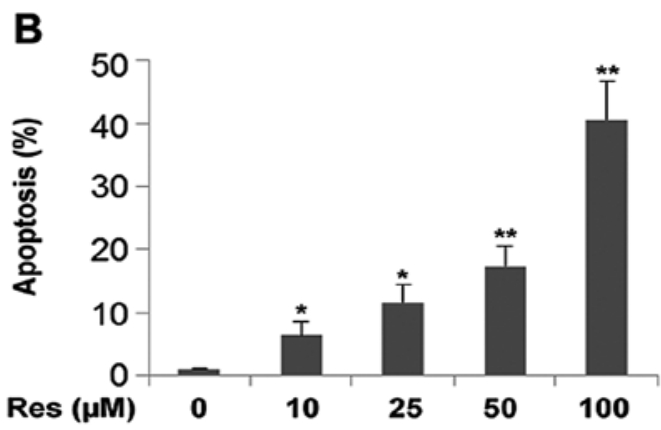

Figure 2. Resveratrol induces apoptosis in human NPC cells. CNE-2Z cells were incubated with increasing concentrations of resveratrol (0-100 $\mu \mathrm{M})$ for $48 \mathrm{~h}$. The cells were stained with Annexin V-FITC/propidium (PI) solution and subjected to flow cytometric analysis. (A) Representative histograms of flow cytometric analysis. (B) Data represent means \pm SD of 3 independent experiments. ${ }^{*} \mathrm{P}<0.05 ;{ }^{* *} \mathrm{P}<0.01$.

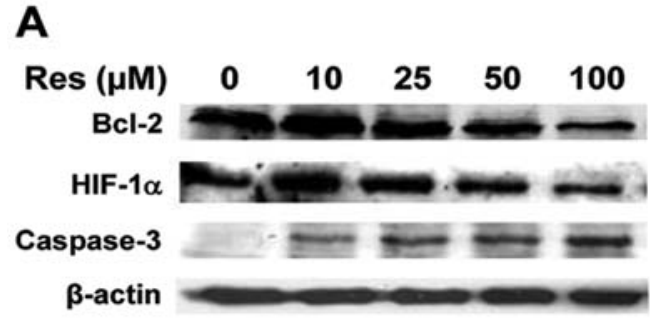

B

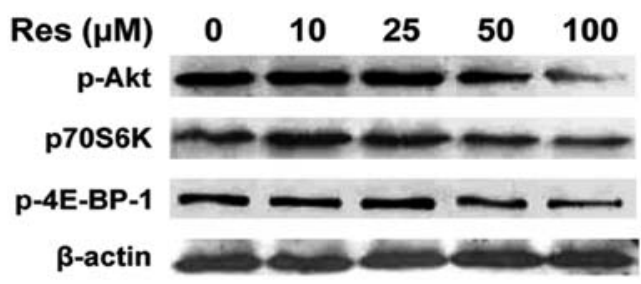

Figure 3. Effects of resveratrol on the expression of apoptosis regulatory genes and the pAkt/p70S6K signaling pathway. CNE-2Z cells were incubated with increasing concentrations of resveratrol $(0-100 \mu \mathrm{M})$ for $16 \mathrm{~h}$, and then whole cell lysates were prepared for western blot analysis. (A) Resveratrol induced changes in the expression of Bcl-2, HIF-1 $\alpha$ and caspase-3 proteins in CNE-2Z cells. (B) Resveratrol induced changes in the phosphorylation of Akt1, p70S6K and p-4E-BP-1 in CNE-2Z cells. Data represent the results of 3 independent experiments.
(Fig. 4A, lower panel). At $50 \mu \mathrm{M}$, resveratrol treatment further decreased the percentage of G1-phase cells $(36.2 \pm 7.9 \%$; $\mathrm{P}<0.01)$ but simultaneously increased the percentage of cells at both the S-phase $(40.5 \pm 8.2 \% ; \mathrm{P}<0.01)$ and $\mathrm{G} 2 / \mathrm{M}$-phases $(16.6 \pm 5.2$ to $25.7 \pm 6.9 \%$; $\mathrm{P}<0.05$ ) (Fig. 4A, lower panel). These findings suggest that resveratrol treatment was able to arrest the cell cycle progression of NPC cells at the S- and G2/M-phases.

To further explore the molecular mechanisms involved in resveratrol-induced alterations in cell cycle distribution of NPC cells, CNE-2Z cells were treated with increasing concentrations of resveratrol for $24 \mathrm{~h}$. Then, the protein expression of several cyclins involved in cell cycle regulation was determined by western blot analysis. We found that resveratrol treatment markedly inhibited the expression of cyclin A, B, D and E, and $\mathrm{CDK} / \mathrm{p} 34$ proteins in CNE-2Z cells, thus further confirming the effects of resveratrol on cell cycle progression in NPC cells.

In vivo effects of resveratrol on NPC growth. To further validate the anticancer effect of resveratrol on NPC, in vivo studies on xenografts of CNE-2Z cells in nude mice were performed. Our results showed that i.p. administration of resveratrol ( $20 \mathrm{mg} / \mathrm{kg}$ body weight) significantly suppressed the growth of xenografted tumors from Day 12 after resveratrol administration $(\mathrm{P}<0.05)$ (Fig. 5A and $\mathrm{B})$. Histological analysis by $\mathrm{H} \& \mathrm{E}$ 

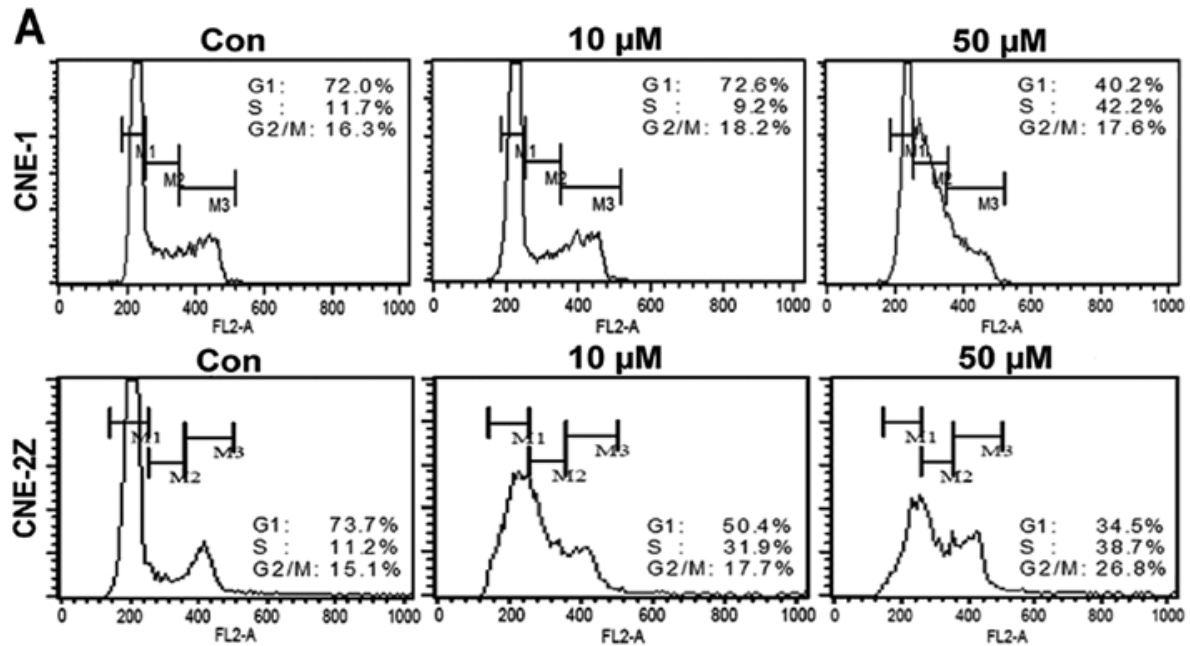

$10 \mu \mathrm{M}$

$50 \mu \mathrm{M}$

B

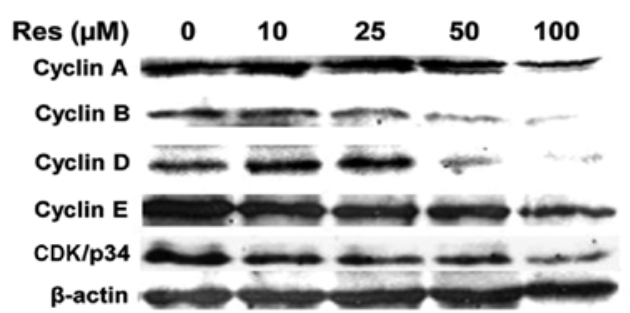

Figure 4. Effects of resveratrol on cell cycle progression in human NPC cells. CNE-1 and CNE2Z cells were exposed to increasing concentrations of resveratrol $(0-100 \mu \mathrm{M})$ for $48 \mathrm{~h}$, and then collected and prepared for flow cytometric analysis of cell cycle distribution. (A) Representative histograms of flow cytometric analysis. (B) CNE-2Z cells were incubated with increasing concentrations of resveratrol $(0-100 \mu \mathrm{M})$ for $16 \mathrm{~h}$, and the expression of cyclins A, B, D, E and $\mathrm{CDK} / \mathrm{p} 34$ proteins was determined by western blot analysis. Data represent the results of 3 independent experiments.
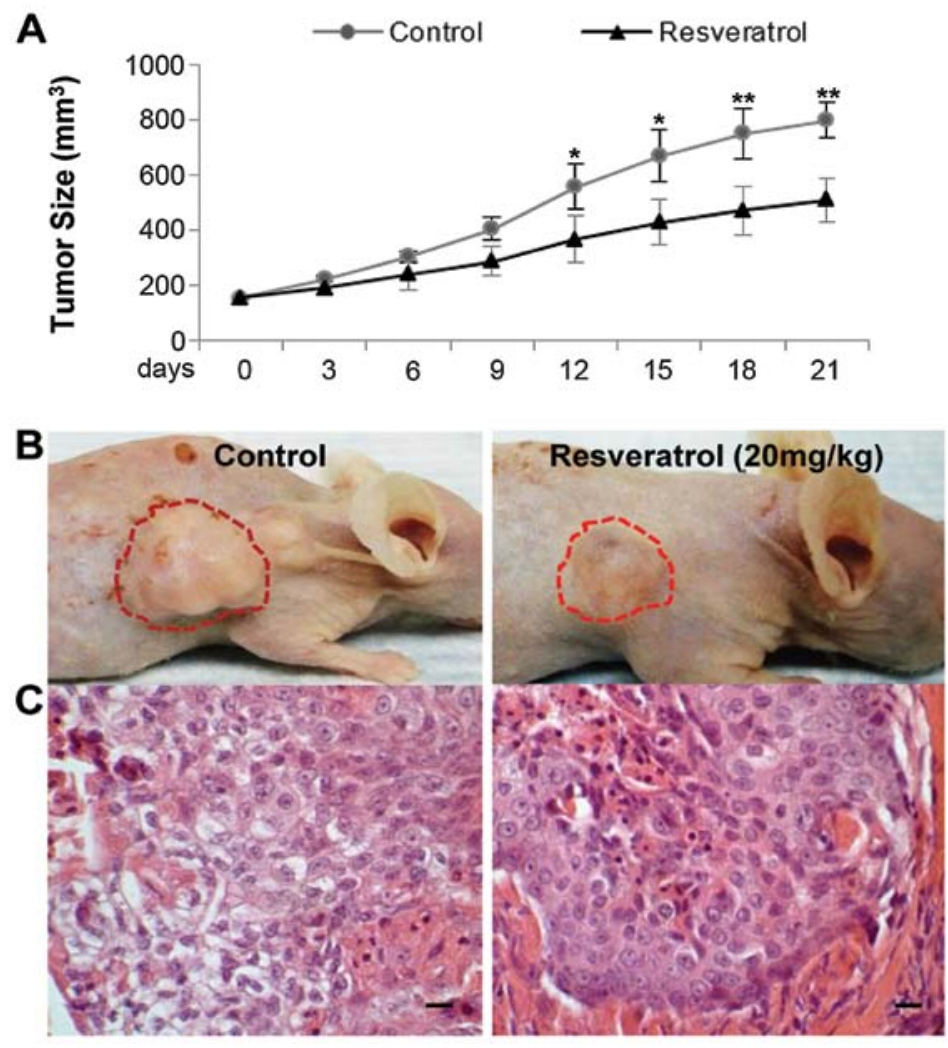

Figure 5. Effects of resveratrol on NPC xenografts in nude mice. CNE-2Z $\left(1 \times 10^{6}\right)$ cells in $0.1 \mathrm{ml}$ PBS were subcutaneously (s.c.) injected into the right hind flank of the mice. One week after inoculation of tumor cells $\left(\sim 100 \mathrm{~mm}^{3}\right)$, the tumor-bearing mice were randomly divided into the control and resveratrol $(20 \mathrm{mg} / \mathrm{kg}$ body weight) treatment groups ( $\mathrm{n}=5 / \mathrm{group})$. Resveratrol was intraperitoneally (i.p.) injected into mice once a day for 3 weeks. Control animals were injected with the vehicle (10\% DMSO in PBS). (A) Tumor growth curve. Tumor sizes were measured every other day with a caliper and were calculated as $1 / 2 \mathrm{x}$ length $\mathrm{x}$ width ${ }^{2}\left(\mathrm{~V}=\mathrm{LW}^{2} / 2 \mathrm{~mm}^{3}\right)$. (B) Representative pictures of grown tumors 3 weeks after resveratrol treatment. (C) Representative H\&E staining images of paraffin-embedded tumor sections. Bars, $100 \mu \mathrm{m}$. Data represent means $\pm \mathrm{SD}$ of 3 independent experiments. ${ }^{*} \mathrm{P}<0.05 ;{ }^{* * * *} \mathrm{P}<0.01$. 
staining indicated that resveratrol-treated tumors appeared to be more organized with fewer cellular components and more collagenous structures (Fig. 5C). Collectively, these results provide substantial evidence that resveratrol possesses potent anticancer effects on human NPC.

\section{Discussion}

A growing body of evidence has shown that resveratrol possesses multiple beneficial effects on health, such as cardioprotective and neuroprotective, anti-aging, anti-inflammatory, antioxidant, and anticancer activities $(8,9)$. In recent years, the anticancer activities of resveratrol have been indicated in numerous in vitro and in vivo studies with various types of cancer and have also been tested in clinical trials (13). It appears that the multiple anticancer activities of resveratrol involve all the hallmarks of cancer (14), including cancer cell proliferation/survival (15), apoptosis (16-18), cell cycle alteration (19-21), angiogenesis (22), metastasis (23), inflammation (23), resistance to chemo- and radio-therapies $(24,25)$, and cancer metabolisms (26). In the present study, we demonstrated that resveratrol can also potently inhibit the growth and induce apoptosis in human NPC cells (Figs. 1, 2 and 5).

At the molecular level, resveratrol-mediated multiple anticancer activities may be due to the wide spectrum of modulatory effects on multiple signaling pathways and downstream transcriptional factors of resveratrol $(8,27)$. The signaling pathways targeted by resveratrol include, but are not limited to, MAPK signaling pathways such as extracellular signal-regulated protein kinases (ERKs), c-Jun N-terminal kinases/stress-activated protein kinases (JNKs/SAPKs), and p38 kinases $(28,29)$, PI-3K/Akt/p70S6K signaling pathways $(17,22,30)$, signal transducer and activator of transcription (STAT)-3 $(20,31)$ and $\mathrm{Wnt} / \beta$-catenin (32) signaling pathways. Furthermore, resveratrol has been shown to inhibit numerous transcriptional factors that are downstream of these signaling pathways, including, but not limited to, $\mathrm{NF}-\kappa \mathrm{B}$, activator protein-1 (AP-1) and HIF-1 $\alpha$ (27). Herein, we demonstrated that resveratrol can significantly inhibit the activation of pAkt/ p70S6K/p-4E-BP-1 signaling pathways as well as the expression of HIF-1 $\alpha$ in NPC cells (Fig. 3), which contribute to its anticancer activities in human NPC.

Previous studies have shown that resveratrol inhibits proliferation of cells by inhibiting cell-cycle progression at different stages depending on the cell contexts, whereby the mechanisms may involve the downregulation of the cyclins/ cyclin-dependent kinases (CDKs) and the upregulation of CDK inhibitors. For instance, Notas et al (19) reported that resveratrol exerts its anti-proliferative effect on HepG2 hepatocellular carcinoma cells by inducing cell cycle arrest at the G1 and G2/M-phases. Studies by Joe et al (21) showed that resveratrol inhibits the growth of several human cancer cell lines by inducing S-phase arrest. Casanova et al (24) showed that resveratrol chemosensitizes breast cancer cells to melphalan by inducing cell cycle arrest at S-phase. In addition, numerous studies have shown that resveratrol can induce apoptosis in various types of cancer cells by downregulating anti-apoptotic proteins such as Bcl-2, Bcl-xL, survivin, inhibitor of apoptosis proteins (IAPs) $(16,19)$, and by upregulating pro-apoptotic proteins such as p53 $(16,28,29)$, Bax/Bad and activating caspases (16). In this study, we demonstrated that treatment of human NPC cells with resveratrol led to the arrest of cell cycle progression at S- and G2/M-phases, which may be attributed to the downregulation of the expression of several cyclins and CDKs (Fig. 4). Resveratrol treatment also significantly inhibited the expression of $\mathrm{Bcl}-2$ and promoted the expression of caspase-3, which may contribute to the induction of apoptosis in human NPC cells (Figs. 2 and 3).

To date, only three in vitro studies have suggested the potential inhibitory effects of resveratrol on human NPC cells (33-35). The underlying molecular mechanisms remain largely unknown, and there is also a lack of in vivo evidence to support the anticancer activity in human NPC. In the present study, we further demonstrated that resveratrol possesses potent anticancer activities in human NPC both in vitro and in vivo, whereby resveratrol-mediated anticancer activities in human NPC may be attributed to its inhibitory effects on cancer cell proliferation as well as to its pro-apoptotic functions. However, more studies are warranted to further explore whether resveratrol can also affect hallmarks of cancer other than proliferation and survival/apoptosis in human NPC. Findings from these studies will lead to the identification of novel molecular targets of resveratrol for efficacious chemoprevention and chemotherapy of human NPC.

\section{Acknowledgements}

This study was financially supported by the Research Foundation for Innovative Team of Guangdong Medical College, China (TD1105) and the Special Fund for Key Laboratories of Medical Molecular Diagnosis of Guangdong Province, China (XZ1001).

\section{References}

1. Parkin DM, Bray F, Ferlay J and Pisani P: Global cancer statistics, 2002. CA Cancer J Clin 55: 74-108, 2005.

2. Pan Y and Claret FX: Targeting Jab1/CSN5 in nasopharyngeal carcinoma. Cancer Lett 326: 155-160, 2012

3. Tao Q and Chan AT: Nasopharyngeal carcinoma: molecular pathogenesis and therapeutic developments. Expert Rev Mol Med 9: 1-24, 2007.

4. Erkal HS, Serin M and Cakmak A: Nasopharyngeal carcinomas: analysis of patient, tumor and treatment characteristics determining outcome. Radiother Oncol 61: 247-256, 2001.

5. O'Sullivan B: Nasopharynx cancer: therapeutic value of chemoradiotherapy. Int J Radiat Oncol Biol Phys 69 (Suppl 2): S118-S121, 2007.

6. Jang M, Cai L, Udeani GO, et al: Cancer chemopreventive activity of resveratrol, a natural product derived from grapes. Science 275 : 218-220, 1997.

7. Aggarwal BB and Shishodia S: Molecular targets of dietary agents for prevention and therapy of cancer. Biochem Pharmacol 71: 1397-1421, 2006.

8. Tyihak E, Kiraly-Veghely Z and Moricz AM: Multiple beneficial effects of resveratrol and their chemical-biochemical basis. Nat Prod Commun 6: 631-638, 2011.

9. Yu W, Fu YC and Wang W: Cellular and molecular effects of resveratrol in health and disease. J Cell Biochem 113: 752-759, 2012.

10. Zhang M, Li X, Zhang Y and Zhou K: Bax inhibitor-1 mediates apoptosis-resistance in human nasopharyngeal carcinoma cells. Mol Cell Biochem 333: 1-7, 2010.

11. Nys K, Maes H, Dudek AM and Agostinis P: Uncovering the role of hypoxia inducible factor-1alpha in skin carcinogenesis. Biochim Biophys Acta 1816: 1-12, 2011.

12. Castaneda CA, Cortes-Funes H, Gomez HL and Ciruelos EM: The phosphatidyl inositol 3-kinase/AKT signaling pathway in breast cancer. Cancer Metastasis Rev 29: 751-759, 2010. 
13. Patel KR, Scott E, Brown VA, Gescher AJ, Steward WP and Brown K: Clinical trials of resveratrol. Ann NY Acad Sci 1215: 161-169, 2011.

14. Hanahan D and Weinberg RA: Hallmarks of cancer: the next generation. Cell 144: 646-674, 2011

15. Schneider Y, Vincent F, Duranton B, et al: Anti-proliferative effect of resveratrol, a natural component of grapes and wine, on human colonic cancer cells. Cancer Lett 158: 85-91, 2000.

16. Lin HY, Tang HY, Davis FB and Davis PJ: Resveratrol and apoptosis. Ann NY Acad Sci 1215: 79-88, 2011.

17. Aziz MH, Nihal M, Fu VX, Jarrard DF and Ahmad N: Resveratrol-caused apoptosis of human prostate carcinoma $\mathrm{LNCaP}$ cells is mediated via modulation of phosphatidylinositol 3'-kinase/Akt pathway and Bcl-2 family proteins. Mol Cancer Ther 5: 1335-1341, 2006.

18. Kuo PL, Chiang LC and Lin CC: Resveratrol-induced apoptosis is mediated by p53-dependent pathway in Hep $\mathrm{G} 2$ cells. Life Sci 72: 23-34, 2002.

19. Notas G, Nifli AP, Kampa M, Vercauteren J, Kouroumalis E and Castanas E: Resveratrol exerts its anti-proliferative effect on HepG2 hepatocellular carcinoma cells, by inducing cell cycle arrest, and NOS activation. Biochim Biophys Acta 1760: 1657$1666,2006$.

20. Kotha A, Sekharam M, Cilenti L, et al: Resveratrol inhibits Src and Stat 3 signaling and induces the apoptosis of malignant cells containing activated Stat3 protein. Mol Cancer Ther 5: 621-629, 2006.

21. Joe AK, Liu H, Suzui M, Vural ME, Xiao D and Weinstein IB: Resveratrol induces growth inhibition, S-phase arrest, apoptosis, and changes in biomarker expression in several human cance cell lines. Clin Cancer Res 8: 893-903, 2002.

22. Zhang Q, Tang X, Lu QY, Zhang ZF, Brown J and Le AD: Resveratrol inhibits hypoxia-induced accumulation of hypoxiainducible factor-1alpha and VEGF expression in human tongue squamous cell carcinoma and hepatoma cells. Mol Cancer Ther 4: 1465-1474, 2005.

23. Salado C, Olaso E, Gallot N, et al: Resveratrol prevents inflammation-dependent hepatic melanoma metastasis by inhibiting the secretion and effects of interleukin-18. J Transl Med 9: 59, 2011.

24. Casanova F, Quarti J, da Costa DC, Ramos CA, da Silva JL and Fialho E: Resveratrol chemosensitizes breast cancer cells to melphalan by cell cycle arrest. J Cell Biochem 113: 2586-2596, 2012.
25. Fang Y, DeMarco VG and Nicholl MB: Resveratrol enhances radiation sensitivity in prostate cancer by inhibiting cell proliferation and promoting cell senescence and apoptosis. Cancer Sci 103: 1090-1098, 2012

26. Iqbal MA and Bamezai RN: Resveratrol inhibits cancer cell metabolism by down regulating pyruvate kinase M2 via inhibition of mammalian target of rapamycin. PLoS One 7: e36764, 2012.

27. Whitlock NC and Baek SJ: The anticancer effects of resveratrol: modulation of transcription factors. Nutr Cancer 64: 493-502, 2012.

28. She QB, Bode AM, Ma WY, Chen NY and Dong Z: Resveratrolinduced activation of p53 and apoptosis is mediated by extracellular-signal-regulated protein kinases and p38 kinase. Cancer Res 61: 1604-1610, 2001.

29. Shih A, Davis FB, Lin HY and Davis PJ: Resveratrol induces apoptosis in thyroid cancer cell lines via a MAPK- and p53-dependent mechanism. J Clin Endocrinol Metab 87: 12231232,2002

30. Pozo-Guisado E, Lorenzo-Benayas MJ and FernandezSalguero PM: Resveratrol modulates the phosphoinositide 3-kinase pathway through an estrogen receptor alpha-dependent mechanism: relevance in cell proliferation. Int J Cancer 109: 167-173, 2004

31. Yang YP, Chang YL, Huang PI, et al: Resveratrol suppresses tumorigenicity and enhances radiosensitivity in primary glioblastoma tumor initiating cells by inhibiting the STAT3 axis. J Cell Physiol 227: 976-993, 2012.

32. Chen HJ, Hsu LS, Shia YT, Lin MW and Lin CM: The $\beta$-catenin/ TCF complex as a novel target of resveratrol in the Wnt $/ \beta$-catenin signaling pathway. Biochem Pharmacol 84: 1143-1153, 2012.

33. Quan F, Zhang SQ, Bai YX, et al: Resveratrol increases sensitivity of CNE2 cells to chemotherapeutic drugs under hypoxia. Zhong Xi Yi Jie He Xue Bao 7: 952-957, 2009 (In Chinese)

34. Chow SE, Wang JS, Chuang SF, et al: Resveratrol-induced p53-independent apoptosis of human nasopharyngeal carcinoma cells is correlated with the downregulation of $\Delta \mathrm{Np} 63$. Cancer Gene Ther 17: 872-882, 2010.

35. Huang TT, Lin HC, Chen CC, et al: Resveratrol induces apoptosis of human nasopharyngeal carcinoma cells via activation of multiple apoptotic pathways. J Cell Physiol 226: 720-728, 2011. 